\title{
Numerical Prediction of the Short-Term Trajectory of Microplastic Particles in Laizhou Bay
}

\author{
Yu Ding ${ }^{1}$, Haifei Liu ${ }^{2, *}$ and Wei Yang ${ }^{1}$ \\ 1 School of Environment, Beijing Normal University, Beijing 100875, China; dingyu@mail.bnu.edu.cn (Y.D.); \\ yangwei@bnu.edu.cn (W.Y.) \\ 2 The Key Laboratory of Water and Sediment Sciences of Ministry of Education, School of Environment, \\ Beijing Normal University, Beijing 100875, China \\ * Correspondence: haifei.liu@bnu.edu.cn
}

Received: 30 August 2019; Accepted: 24 October 2019; Published: 27 October 2019

\begin{abstract}
Microplastic particles are easily captured by microorganisms and enter the food chain, which poses a threat to ecological health. These particles are abundant in coastal areas because of the influence of anthropic activities and the interaction between the sea and land. Although much research on microplastics has been done, predicting the transportation of microplastic particles in coastal zones is still a challenge. In this paper, the trajectories of microplastic particles released from four river mouths around Laizhou Bay are investigated using the lattice Boltzmann method coupled with the Lagrangian particle-tracking method, involving inter-particle and particle-wall collisions. The trajectories of particles released from four river mouths are recorded within 30 days.
\end{abstract}

Keywords: movement trajectory; microplastic particles; lattice Boltzmann method; Laizhou Bay; Lagrangian particle-tracking method

\section{Introduction}

Plastic debris is frequently found in rivers, lakes and oceans. The transportation of plastic debris needs the entrainment of water flows. Although its degradation process is extremely sluggish, plastic can be broken down into small particles during its transportation. Plastic particles with a diameter less than $5 \mathrm{~mm}$ are recognized as microplastics [1]. These particles can remain in the soil and sediment for hundreds of years and even longer [2]. In the meantime, microplastics may be captured by marine life and then transferred into the food chain. The microplastics themselves are harmful substances the are poisonous to living beings [3]. Hence, as a persistent pollutant, the study of microplastics has provoked much attention.

Currently, many microplastics are accumulated in coastal zones, released by land sources (tourist beaches, factory sewage and rivers) and marine sources (ship transport, fishing and marine cultivation). Browne et al. [4] tested the impact of the wind and the deposition mode on the spatial distribution of microplastics in the Tamar Estuary, the U.K. Law et al. [5] studied the concentration of the floating microplastics in the surface water of the North Atlantic. Dubaish and Liebezeit [6] studied the distribution of microplastics and black carbon particles in the surface water of Jade System, Germany. Nor and Obbard [7] investigated and categorized the microplastics extracted from sediment in several mangrove habitats in Singapore. Còzar [2] provided the worldwide distribution of microplastics and predicted the accumulation sites. In the following year, Còzar [8] studied the suspended plastics in the Mediterranean Sea and evaluated the pollution level. The existing research is focused on the sampling process, categorizing, identifying the source and assessing the ecological effect of the microplastics. However, the trajectories of microplastic particles need more attention. The area with more particle trajectories enhances the chance captured by the marine creature and should not be selected as a 
marine agriculture zone. These trajectories also provide an optimized area for the recycle process of microplastic particles.

The movement of microplastic particles in flows can be described as fluid-solid two-phased flow. Usually, this problem is simulated by the Eulerian or Lagrangian method. For the former method, those particles are treated as a continuum, which is not suitable for the cased with less quantity of particles. However, the Lagrangian one can demonstrate the trajectories of individual particles and dealing with the inter-particle collision and the particle-wall collision according to particles' properties. Many research describe the particle-tracking method [9-11] and inter-particle collision [12-16]. Commonly, these models were applied to the sediment dynamics simulation as well $[17,18]$. The model proposed by Tanaka and Tsuji [12] is adopted in this paper.

The numerical method in this paper is the lattice Boltzmann method (LBM), developed into a general calculation in hydrodynamic modelling for its efficiency, simplicity and accuracy. The theory of the LBM in shallow water simulation shows a good performance for flow with complex boundary conditions and source terms [19-22]. This method can also deal the wetting-drying process on a dry bed with the wet-dry interface treatment [23]. Its inborn nature of both Eulerian and Lagrangian attributes [24] is benefit for coupling with Lagrangian particle-tracking method. These advantages make the LBM performing better in modelling the trajectories of microplastic particles.

This paper took Laizhou Bay as the study area and investigated the movement trajectory of microplastic particles. Laizhou Bay lies in the south of Bohai Sea, Shandong Province, China. In this area, there are many rivers flowing into the sea, such as the Yellow River, the Wei River and the Yu River [25]. This area has been severely exposed to anthropic activities, which produces microplastics by means of garbage dumping, fishing cultivation and local tourism [26]. Considering a great number of factories and domestic sewage flows into Laizhou Bay through rivers, this study focuses on predicting the trajectories of microplastic particles, which are discharged from the river mouth in this region, to determine the trajectory and the moving range of these microplastics.

\section{Governing Equations}

\subsection{Shallow Water Equations}

Considering that the vertical scale is far smaller than the horizontal scale in Laizhou Bay, this two-dimensional hydrodynamic field can be simulated based on shallow water equations [27], stated as

$$
\begin{gathered}
\frac{\partial h}{\partial t}+\frac{\partial\left(h u_{j}\right)}{\partial x_{j}}=0 \\
\frac{\partial\left(h u_{i}\right)}{\partial t}+\frac{\partial\left(h u_{i} u_{j}\right)}{\partial x_{j}}=-\frac{g \partial h^{2}}{2 \partial x_{i}}+v \frac{\partial^{2}\left(h u_{i}\right)}{\partial x_{j} \partial x_{j}}+F_{i}
\end{gathered}
$$

where $h$ is the water depth; $t$ is time; $u$ is the flow velocity; $x$ is the Cartesian coordinate; $g$ is the gravitational acceleration; and $F_{i}$ is the force term in the $i$ direction, determined as

$$
F_{i}=-g h \frac{\partial z_{b}}{\partial x_{i}}+\frac{\tau_{w i}}{\rho}-\frac{\tau_{b i}}{\rho}+E_{i}
$$

where $z_{b}$ is the bed elevation; $\rho$ is the water density; $\tau_{w i}$ is the wind shear stress and is governed by $\tau_{w i}=\rho_{a} C_{w} u_{w i} \sqrt{u_{w j} u_{w j}}$, in which $\rho_{a}$ is the density of air; $C_{w}$ is the resistance coefficient; $u_{w i}$ is the component of the wind velocity in $i$ direction; $\tau_{b i}$ is the bed shear stress and is given by $\tau_{b i}=\rho C_{b} u_{i} \sqrt{u_{j} u_{j}}$, where $C_{b}$ is the coefficient of bed friction and is expressed as $C_{b}=g n_{b}^{2} / h^{1 / 3}$ and $n_{b}$ is the Manning's coefficient at the bed; $E_{i}$ is the Coriolis term, defined as 


$$
E_{i}= \begin{cases}f_{c} h v, & i=x, \\ -f_{c} h u, & i=y,\end{cases}
$$

in which $f_{c}=2 \omega \sin \phi ; \omega$ is the rotation of earth, given by $\omega \approx 7.3 \times 10^{-5} \mathrm{rad} / \mathrm{s} ; \phi$ is the latitude of the study area.

\subsection{Microplastic Dynamics}

Considering that the microplastic particles are very small and hydrophobic, these particles are treated as Lagrangian particles. They are assumed floating on the surface constantly, and the position of particles can be predicted by

$$
\begin{gathered}
\frac{d x_{m j}}{d t}=u_{m j}, \\
\frac{d u_{m j}}{d t}=\frac{3 v C_{D} R e_{m}}{4 d_{m}^{2} S}\left(u_{j}-u_{m j}\right),
\end{gathered}
$$

in which $x_{m j}$ is the position of microplastic particle $j$; Subscript $m$ donates the microplastic particles; $u_{m j}$ is the velocity of microplastic particle $j ; u_{j}$ is the flow velocity; $d_{m}$ is the diameter of microplastic particles and $S$ is the ratio of microplastic particle density to fluid density. $R e_{m}$ is the Reynolds number of microplastic particles and $C_{D}$ is the drag coefficient, defined as below.

$$
\begin{gathered}
\quad R e_{m}=\frac{d_{m}\left|u_{j}-u_{m j}\right|}{v}, \\
C_{D}= \begin{cases}\frac{24}{R e_{m}}, & \operatorname{Re}_{m}<1 ; \\
\frac{24}{R e_{m}}\left(1+0.15 \operatorname{Re}_{m}^{0.687}\right), & 1<\operatorname{Re}_{m}<1000 ; \\
0.44, & \operatorname{Re}_{m}>1000 .\end{cases}
\end{gathered}
$$

\section{Methods}

\subsection{Lattice Boltzmann Method}

The lattice Boltzmann method is selected as the numerical method, by virtue of its efficiency and flexibility. The lattice Boltzmann method is a completely discrete mesoscopic model that treats the fluid as fractional particles in regular lattices, providing a promising approach to complex partial differential equations such as the shallow water equations [28].

To simulate the hydrodynamic field, the lattice Boltzmann method was used, and the lattice Boltzmann equation is given by

$$
f_{\alpha}\left(\mathbf{x}+\mathbf{e}_{\alpha} \Delta t, t+\Delta t\right)-f_{\alpha}(\mathbf{x}, t)=-\frac{1}{\tau}\left(f_{\alpha}-f_{\alpha}^{e q}\right)+W_{\alpha} \frac{3 \Delta t}{e^{2}} e_{\alpha i} F_{\alpha}(\mathbf{x}, t), \alpha=0 \sim 8,
$$

in which $f_{\alpha}$ is the distribution function of fictional particles in the $\alpha$ direction, $f_{\alpha}^{e q}$ is the local equilibrium function and $\tau$ is the relaxation time. $W_{\alpha}$ is the weight coefficient is given by Equation (10), employing the $\mathrm{D} 2 \mathrm{Q} 9$ lattice pattern as Figure 1. $F_{\alpha}$ is the force component in $\alpha$ direction.

$$
W_{\alpha}= \begin{cases}\frac{4}{9}, & \alpha=0 \\ \frac{1}{9}, & \alpha=1,3,5,7 \\ \frac{1}{36}, & \alpha=2,4,6,8\end{cases}
$$


The lattice speed $e$ is determined by

$$
e=\Delta x / \Delta t
$$

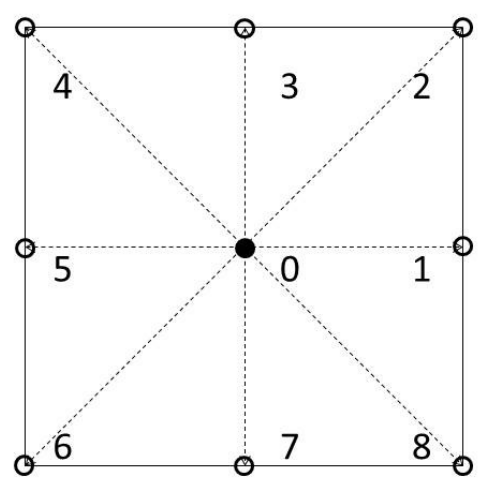

Figure 1. Sketch of D2Q9 lattice pattern.

The particle velocity vector $e_{\alpha}$ is shown as

$$
e_{\alpha}= \begin{cases}(0,0), & \alpha=0 \\ e\left[\cos \frac{(\alpha-1) \pi}{4}, \sin \frac{(\alpha-1) \pi}{4}\right], & \alpha=1,3,5,7 \\ \sqrt{2} e\left[\cos \frac{(\alpha-1) \pi}{4}, \sin \frac{(\alpha-1) \pi}{4}\right], & \alpha=2,4,6,8\end{cases}
$$

The local equilibrium distribution function is expressed as

$$
f_{\alpha}^{e q}= \begin{cases}h-\frac{5 g h^{2}}{6 e^{2}}-\frac{2 h}{3 e^{2} u_{i} u_{i}}, & \alpha=0 \\ \frac{g h^{2}}{6 e^{2}}+\frac{h}{3 e^{2}} e_{\alpha i} u_{i}+\frac{h}{2 e^{2}} e_{\alpha i} e_{\alpha j} u_{i} u_{j}-\frac{h}{6 e^{2}} u_{i} u_{j}, & \alpha=1,3,5,7 \\ \frac{g h^{2}}{24 e^{2}}+\frac{h}{12 e^{2}} e_{\alpha i} u_{i}+\frac{h}{8 e^{2}} e_{\alpha i} e_{\alpha j} u_{i} u_{j}-\frac{h}{24 e^{2}} u_{i} u_{j}, & \alpha=2,4,6,8\end{cases}
$$

The macroscopic water depth and velocity can be calculated by

$$
\begin{gathered}
h(\mathbf{x}, t)=\sum_{\alpha} f_{\alpha}(\mathbf{x}, t), \\
u_{i}(\mathbf{x}, t)=\frac{1}{h(\mathbf{x}, t)} \sum_{\alpha} e_{\alpha i} f_{\alpha}(\mathbf{x}, t) .
\end{gathered}
$$

According to Equation (5), the position of microplastic particle at time $t+\Delta t$ can be obtained as

$$
x_{m j}^{t+\Delta t}=u_{m j}^{t} \Delta t+x_{m j}^{t}
$$

where $x_{m j}^{t+\Delta t}$ is the position of microplastic particle $j$ at time $t+\Delta t, x_{m j}^{t}$ is the position of microplastic particle $j$ at time $t$ and $u_{m j}^{t}$ is velocity of microplastic particle $j$ at time $t$, given as

$$
u_{m j}^{t+\Delta t}=\frac{3 v C_{D} R e_{p} \Delta t}{4 d_{m}^{2} S}\left(u_{i}^{t}-u_{m j}^{t}\right)+u_{m j}^{t} .
$$

\subsection{Inter-Particle Collision}

To investigate the influence extent of particles collision to trajectories, the inter-particle collision model is employed. The microplastic particles are assumed floating on the water surface and their trajectories could be affected by inter-particle collisions. When the concentration of particles is low, 
the binary collision model is adopted [12]. In this study, the particles are rigid, and the collision occurs instantaneously. This critical step of this model is obeying the law of conservation of momentum.

\subsubsection{Collision Identification}

The total number of particles is $N$ in the computational field. In each computational step, $N(N-1) \times 2$ pairs of particles should be checked for the collision identification. Take particles $i$ and $j$ as an example to show the identifying progress; assume particle $i$ is advanced to particle $j$ and the relative motion of these two particles is demonstrated in Figure 2. The distance of these two particles is $\boldsymbol{R}_{0}$ in time $t$ and $\boldsymbol{R}_{\Delta t}$ in time $t+\Delta t$. The relative position is $\boldsymbol{R}_{c}=\boldsymbol{R}_{0}+k\left(\boldsymbol{R}_{\Delta t}-\boldsymbol{R}_{0}\right)$, in which $k$ is a factor of the nondimensional time scale. The occurrence of the collision requires that the following equation has two real roots, $k 1$ and $k 2(k 1<k 2,0 \leq k 1 \leq 1)$.

$$
\left|\boldsymbol{R}_{0}+k\left(\boldsymbol{R}_{\Delta t}-\boldsymbol{R}_{0}\right)\right|^{2}=d_{m}^{2}
$$

in which $d_{m}$ is the diameter of microplastic particles.

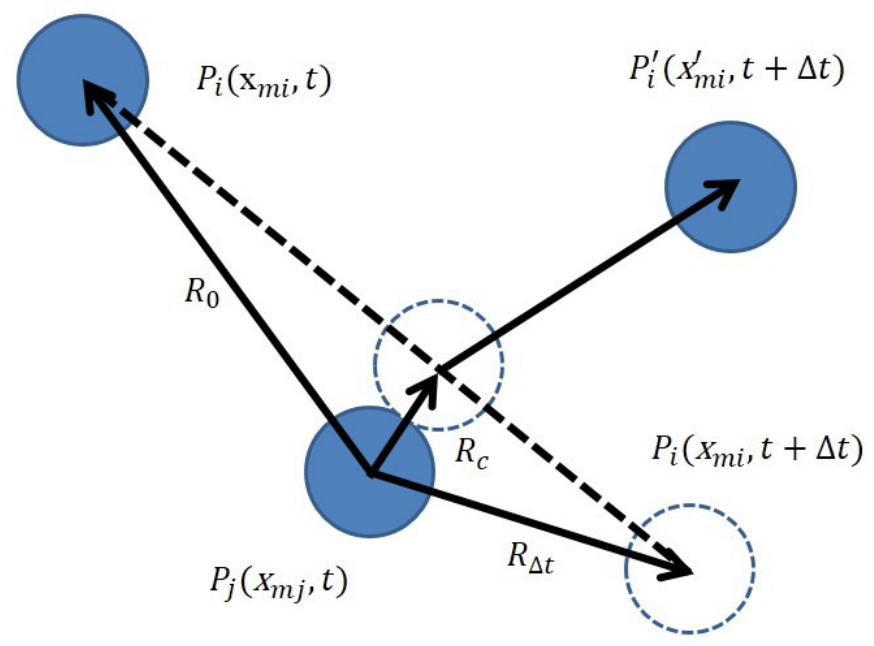

Figure 2. Sketch of binary collision.

\subsubsection{Post-Collision Quantities}

After collision, the velocities of the collision pair can be obtained as

$$
\begin{aligned}
& \boldsymbol{u}_{m i}^{\prime}=\boldsymbol{u}_{m i}+\boldsymbol{J} / m_{m} \\
& \boldsymbol{u}_{m j}^{\prime}=\boldsymbol{u}_{m j}-\boldsymbol{J} / m_{m}
\end{aligned}
$$

where $\boldsymbol{u}_{m i}$ and $\boldsymbol{u}_{m j}$ are precollision velocities of particles $i$ and $j$. $\boldsymbol{J}$ is the impulsive force, consisting of the normal $J_{n}$ and the tangential $J_{t}$ components.

$$
\begin{gathered}
\boldsymbol{J}=J_{n} \boldsymbol{n}+J_{t} \boldsymbol{t}, \\
J_{n}=\frac{(1+e) \boldsymbol{c} \cdot \boldsymbol{n}}{1 / m_{i}+1 / m_{j}}, \\
J_{t} t=\min \left[-\mu J_{n}, \frac{2\left|\boldsymbol{c}_{f c}\right|}{7\left(1 / m_{i}+1 / m_{j}\right)}\right],
\end{gathered}
$$


in which $c$ is the precollision relative velocity, $\boldsymbol{c}=\boldsymbol{u}_{j}^{m}-\boldsymbol{u}_{i}^{m}, \boldsymbol{n}$ is the normal unit velocity of the relative precollision position, $\boldsymbol{n}=\boldsymbol{R}_{c} /\left|\boldsymbol{R}_{c}\right|, t$ is the tangential unit vector of the slip velocity, and $\boldsymbol{c}_{f c}$ is the tangential component of $c$.

The post-collision position of particles $i$ and $j$ is updated as

$$
\begin{aligned}
& \mathbf{x}_{m i}^{\prime}=\mathbf{x}_{m i}+\boldsymbol{u}_{m i} k 1 \Delta t+\boldsymbol{u}_{m i}^{\prime}(1-k 1) \Delta t, \\
& \mathbf{x}_{m j}^{\prime}=\mathbf{x}_{m j}+\boldsymbol{u}_{m j} k 1 \Delta t+\boldsymbol{u}_{m j}^{\prime}(1-k 1) \Delta t,
\end{aligned}
$$

in which $\mathbf{x}_{m}^{\prime}$ is the post-collision position, and $\mathbf{x}_{m}$ is the precollision position.

\subsection{Particle-Wall Collision}

The particle-wall collision frequently occurs near riverbanks and seashores. To address the complex irregular boundary shape, the lattice Boltzmann method requires that the computational domain is covered with lattices, and then, the solid boundary is converted to a denoted value stored in the center of the lattices. To begin, considering the particles are in a meshless system, it is necessary to determine the lattice where the particle located to decide whether the particle will collide with wall or not. Taking the particle collision with lower boundary as an example, except for the particle on the solid boundary, there are four lattices surrounding a particle. Select the nearest lattice position and check its solid data. A solid lattice indicates that this particle collided with wall during the time $(t-\Delta t, t)$. Second, determine the particle position $\left(\mathbf{x}_{m i}, t-\Delta t\right)$ at time $t-\Delta t$ and the location of this collision $\left(\left(\mathbf{x}_{\text {collide }}, t+t w-\Delta t\right)\right)$, as shown in Figure 3. $t_{w}$ is the time before the collision, defined by $t_{w}=\left|\mathbf{x}_{m i}-\mathbf{x}_{\text {collide }}\right| / u_{m i}$, where $u_{m i}$ is the velocity before the collision. Finally, post-collision velocity is calculated by Equations (19), (21)-(23), where $m_{j}$ is equal to positive infinity [29]. The post-collision position at time $t$ is

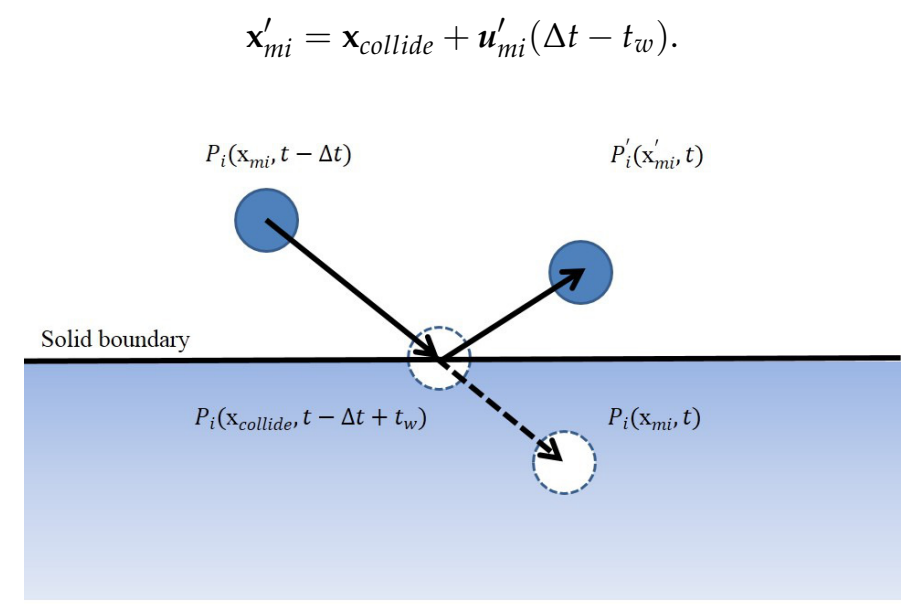

Figure 3. Sketch of particle-wall collision.

\section{Case Study}

\subsection{Model Setup}

Laizhou Bay (Figure 4) is one of the three bays in Bohai Sea, belonging to Shandong Province [30]. More than ten rivers, such as the Yu River and the Wei River, flow into this bay and carry sediment particles and nutrient substance into Laizhou Bay, building the habitat of natural animals and providing fishery resources [25]. However, with the increasing influence of anthropic activities, the sea water is polluted by different pollutants [26], one of which is microplastics. The degraded microplastic particles are transported with the sewage discharging into rivers and then flows into the sea. 
The position and the bottom elevation of Laizhou Bay are demonstrated in Figure 5. This computational field is divided into $140 \times 230$ square lattices $(\Delta x=460 \mathrm{~m})$. The north border of this area is set to the tidal boundary of $12 \mathrm{~h}$ period, as shown in Figure 6 . The east water border is the open boundary, next to the shoreline, where the wet-dry boundary is used [31]. The most frequent wind is considered: SSW wind with an average speed of $2.5 \mathrm{~m} / \mathrm{s}$ (with $\rho_{\alpha}=1.205$ and $C_{w}=0.0026$ ). The initial water depth is $20 \mathrm{~m}$ and the velocity is $0 \mathrm{~m} / \mathrm{s}$. The time step is $4 \mathrm{~s}$. The Manning coefficient of the bottom roughness is 0.01 . Four groups of microplastic particles are released from the following four river mouths: the Yu River, the Di River, the Wei River and the Jiaolai River and numbered as Groups 1-4, respectively. They are released at the same time. Each group has 81 particles, equally distributed in a lattice (Figure 7). All particles are assumed floating on the water surface and the density of particles is $850 \mathrm{~kg} / \mathrm{m}^{3}$. The initial velocity of these particles is $0 \mathrm{~m} / \mathrm{s}$.

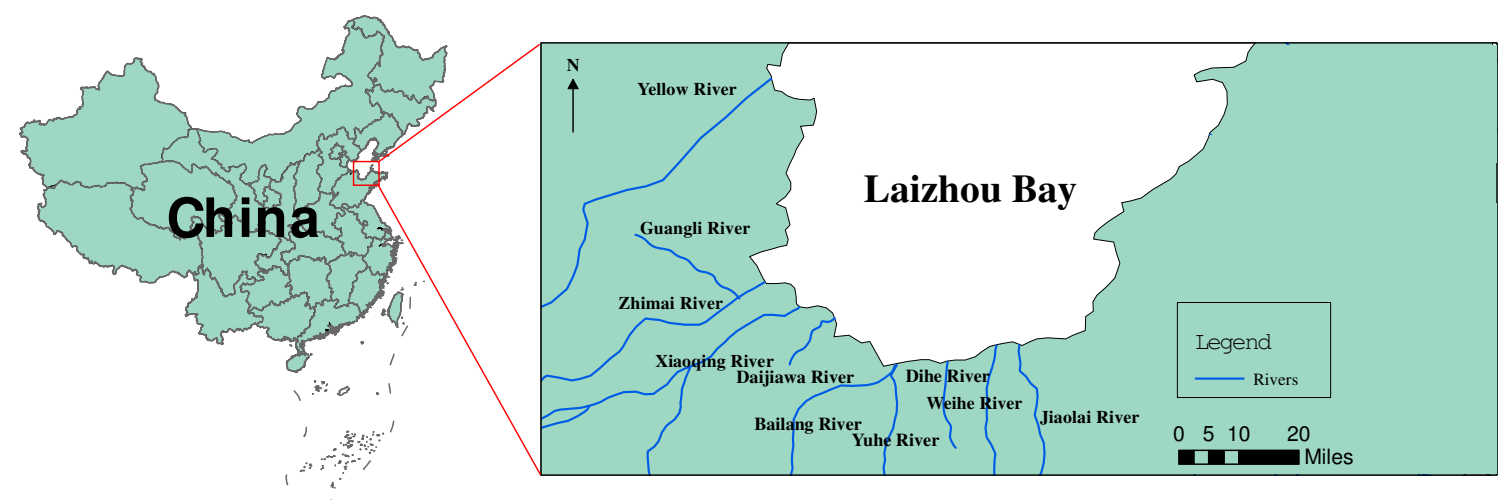

Figure 4. Map of Laizhou Bay.

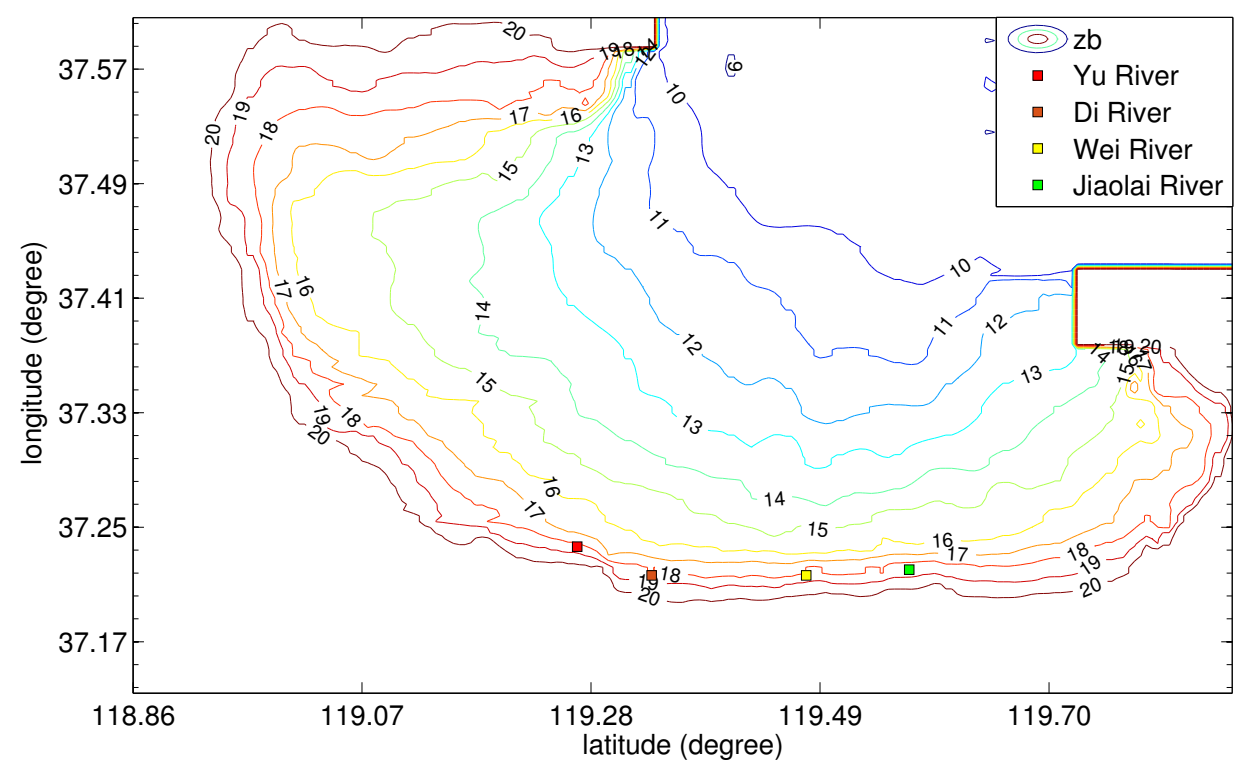

Figure 5. The position and the bottom elevation of Laizhou Bay (referencing to the datum level of the Yellow Sea). 


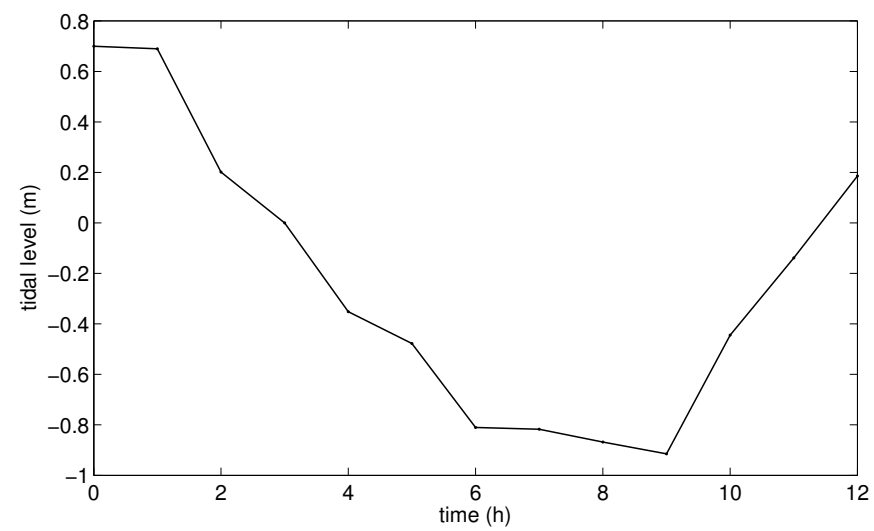

Figure 6. The tidal curve of the north boundary.

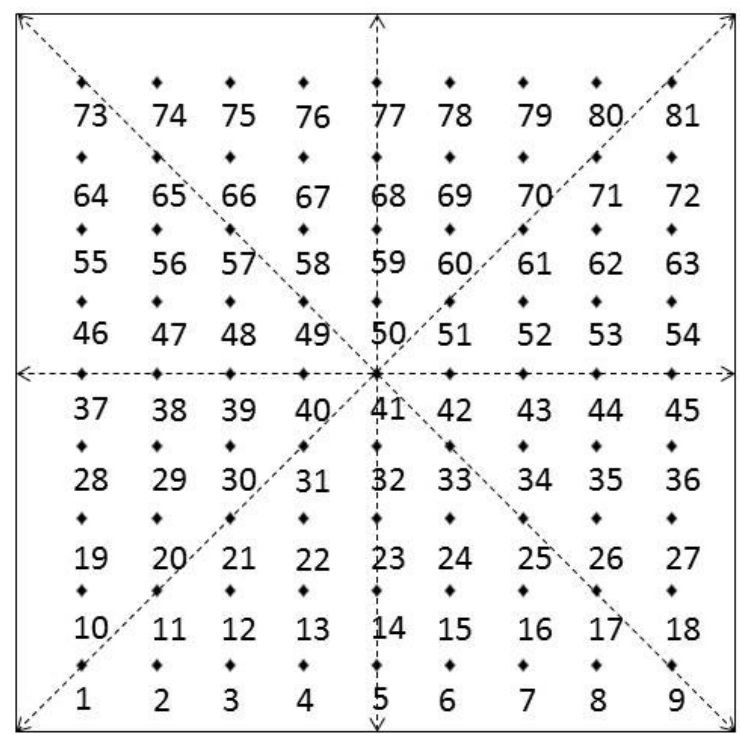

Figure 7. The layout of 81 microplastic particles in a lattice.

This model is validated by the measured value of two sites in Laizhou Bay, Weifang Harbor and Laizhou Port [31]. In Figure 8, the results show a good agreement with the measured data, with less than $15 \%$ error, demonstrating the well accuracy of this numerical model.
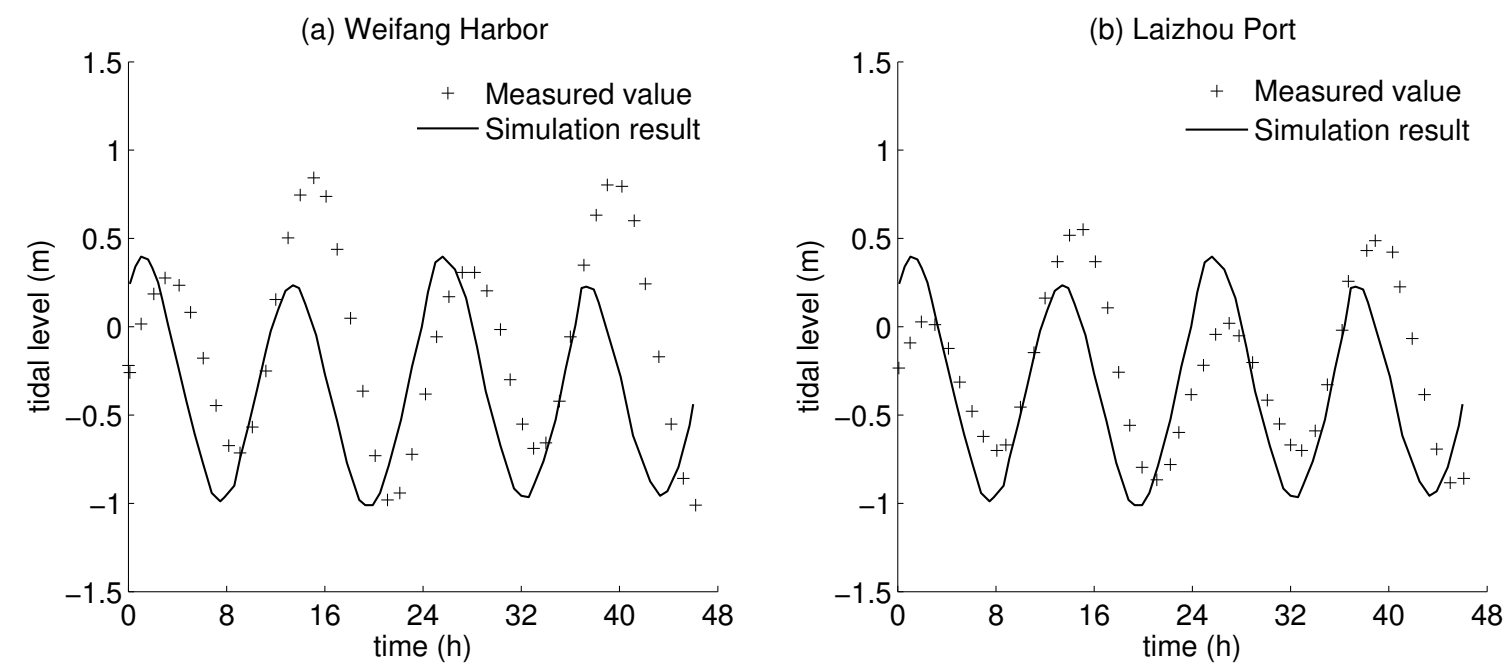

Figure 8. The validation of tidal data in Weifang Harbor (a) and Laizhou Port (b). 
The hydrodynamic model is run for $24 \mathrm{~h}$ to obtain a well-developed flow field and then reset the computational time to 0 . Considering that the hydrodynamic condition in this bay is varying with the tidal, the trajectories of microplastic particles are varying correspondingly. Hence, the release time of 324 microplastic particles at 4 river mouths are (1) $0 \mathrm{~h}$, (2) $3 \mathrm{~h}$, (3) $6 \mathrm{~h}$ and (4) $9 \mathrm{~h}$, which are used to investigate the influence of the hydrodynamic condition on particle transportation.

\subsection{Results and Discussion}

\subsubsection{Particles Input at $t=0 \mathrm{~h}$}

There are four groups of particles released from the four river mouths at $t=0 \mathrm{~h}$ in this section, respectively. The particles numbered 1 of each group are selected as representative, and their trajectory are recorded within $24 \mathrm{~h}$. Figures 9-16 demonstrate the trajectories of these particles in the following four time periods: $0-6 \mathrm{~h}, 6-12 \mathrm{~h}, 12-18 \mathrm{~h}$ and $18-24 \mathrm{~h}$, respectively. $x$ is the distance in the lateral direction and $y$ is the distance in the longitudinal direction. The units are in meters. The origin is located at $\left(118.86^{\circ} \mathrm{E}, 37.09^{\circ} \mathrm{N}\right)$. At time $t=0$ (Figure 9), these particles are in the initial position and then move with the water flow. During this period, the transport distance of the particle in Group 4 is the largest, while Group 1 is the smallest. Figure 10 shows the amplified diagram of trajectories of 4 particles and the velocity fields at $t=0,3,6 \mathrm{~h}$. At $t=0 \mathrm{~h}$, the flow moves toward the offshore direction, then it moves eastward at $t=3 \mathrm{~h}$ and southwestward at $t=6 \mathrm{~h}$. The movement direction of particles is changing along with the flow direction. The particle of Group 1 starts from $(36,156$, $17,296)$. At first, it moves northeastward to $(36,828,18,312)$ and then moves back to $(36,560,17,460)$. During the first six hours, it travels $2111 \mathrm{~m}$, and the absolute distance is $436 \mathrm{~m}$. Similarly, the particles in Groups 2 and 3 start from $(42,136,14,996)$ and $(54,556,14,996)$ and transport northeast to $(43,338$, $16,433)$ and $(55,703,17,187)$, respectively. Eventually, they reach $(43,140,15,220)$ and $(55,959,15,062)$. They move approximately $3102 \mathrm{~m}$ and $4613 \mathrm{~m}$, and the absolute distances are $1028 \mathrm{~m}$ and $1404 \mathrm{~m}$. The particle in Group 4 moves from $(62,836,15,456)$ northeast to $(62,731,18,285)$ and stays at $(63,118$, $15,264)$. Although its movement distance is the largest $(5876 \mathrm{~m})$, the absolute distance is only $341 \mathrm{~m}$ by the end of this period.

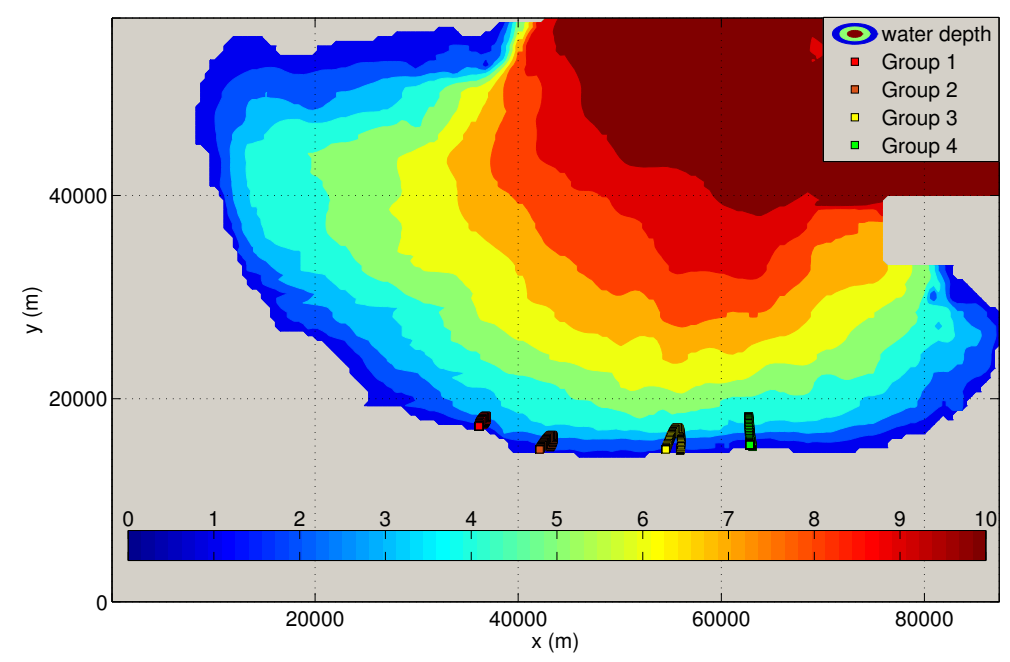

Figure 9. The trajectories of 4 particles during 0-6 h. 


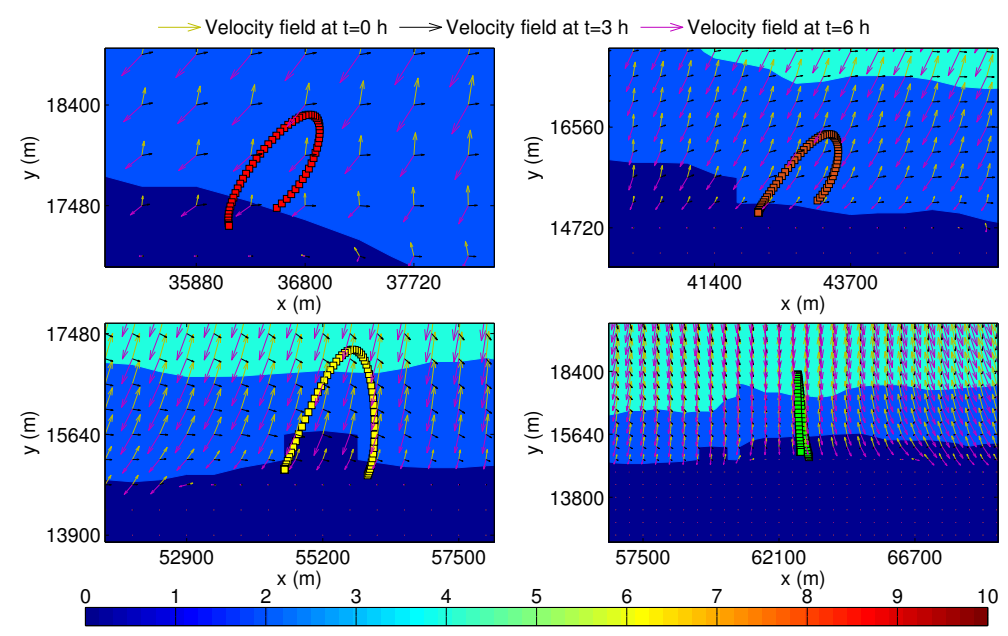

Figure 10. The amplified diagram of trajectories of 4 particles during 0-6 h.

Unlike the previous situation, the traveling distances in Figure 11 are shorter, and the general tendency is towards the shore during 6-12 h. The particles in Group 1, 2 and 3 are transported from the final position of the first $6 \mathrm{~h}$ period to $(35,261,17,140),(41,537,14,779)$ and $(54,088,14,829)$. Their transport distance is basically equal to the absolute distance as $1338 \mathrm{~m}, 1663 \mathrm{~m}$ and $1886 \mathrm{~m}$. During this period, apparently, the particle in Group 4 collides on the shore at $(63,213,15,181)$ and then bounces back to $(63,183,15,230)$ at the end, moving approximately $184 \mathrm{~m}$. The cumulative collision number of 81 particles in Group 3 is 431 during this period (Figure 13), while there is no collision that occurs between particles of other groups. Although collide happens, it merely influences changing trajectories of particles.

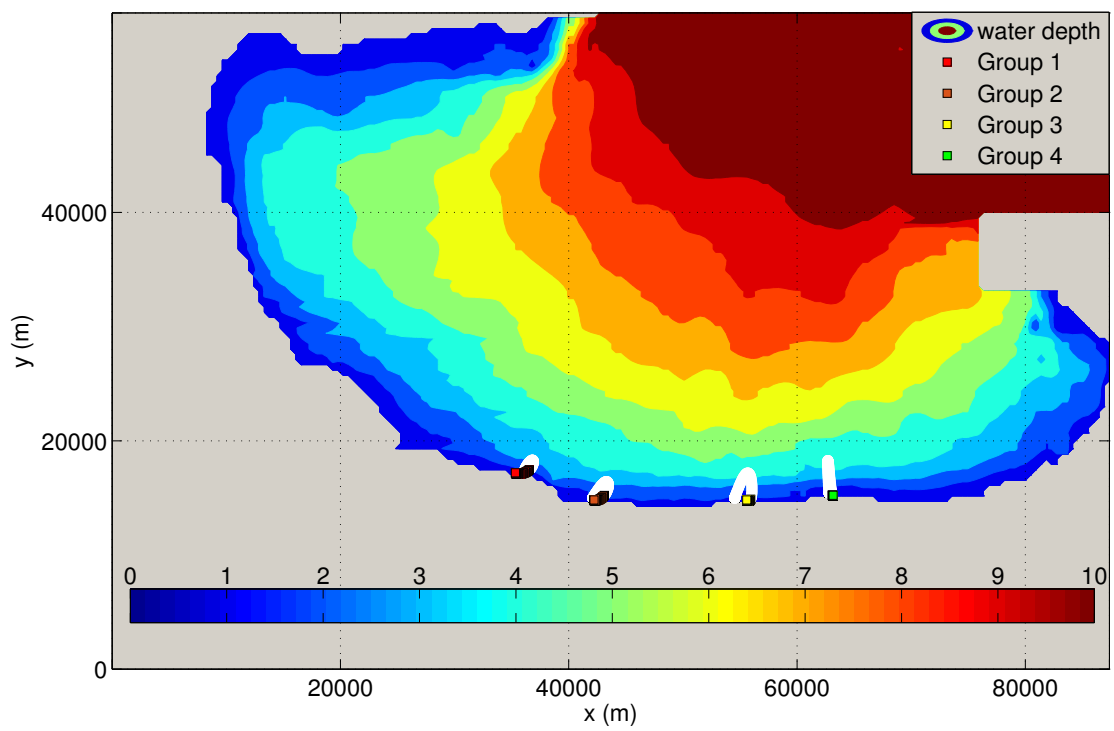

Figure 11. The trajectories of 4 particles during $6-12 \mathrm{~h}$. 


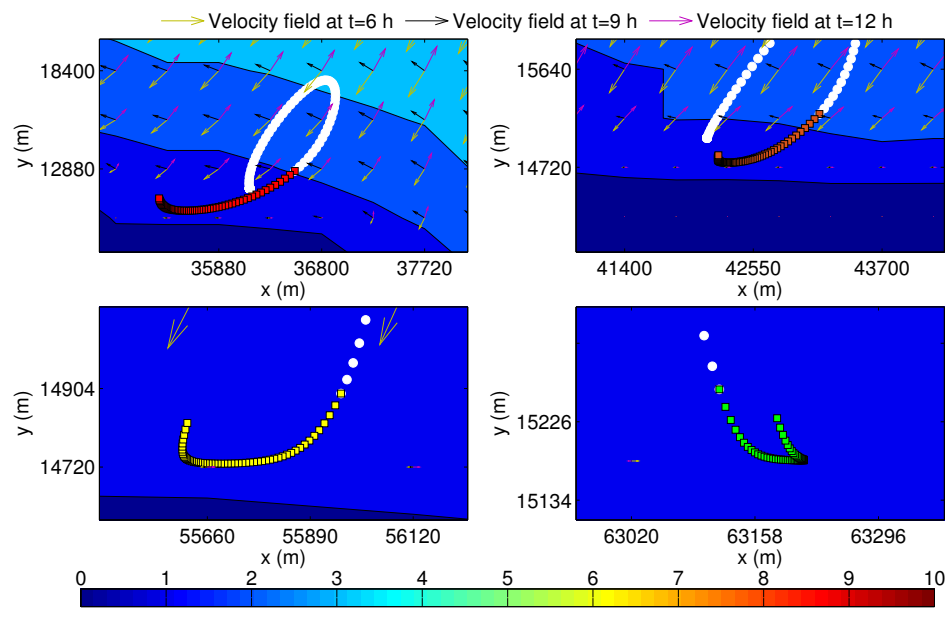

Figure 12. The amplified diagram of trajectories of 4 particles during 6-12 h.

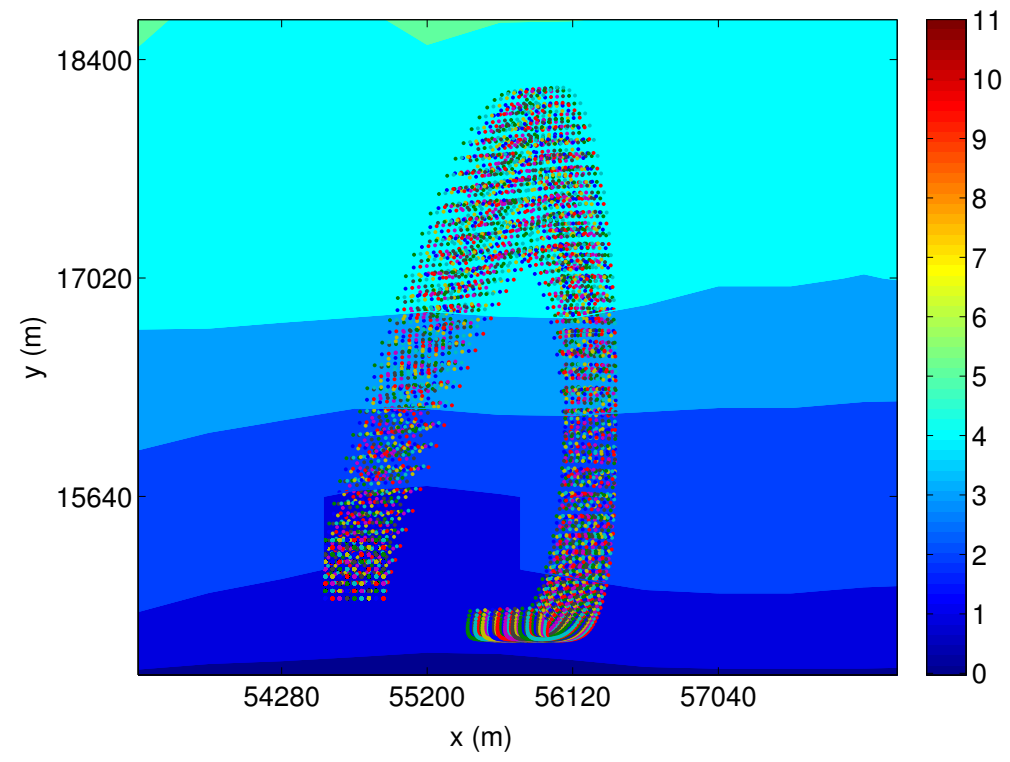

Figure 13. The trajectories of 81 particles in Group 3 during 6-12 h.

The trajectories of particles during 12-18 $\mathrm{h}$ and $18-24 \mathrm{~h}$ are similar to those during $0-6 \mathrm{~h}$ and $6-12 \mathrm{~h}$ (Figures 14-17), while the transport distances are shorter. During 12-18 h, the transport distances in Groups 1-4 are 1302 m, 1899 m, $3110 \mathrm{~m}$ and 3510 m, respectively. No collision happens in this period. In the last six hours, the particles in four groups are moving $969 \mathrm{~m}, 671 \mathrm{~m}, 219 \mathrm{~m}$ and $123 \mathrm{~m}$. The collision number during 18-24 h is 801, of which 191 happen in Group 3 and 610 in Group 4. 


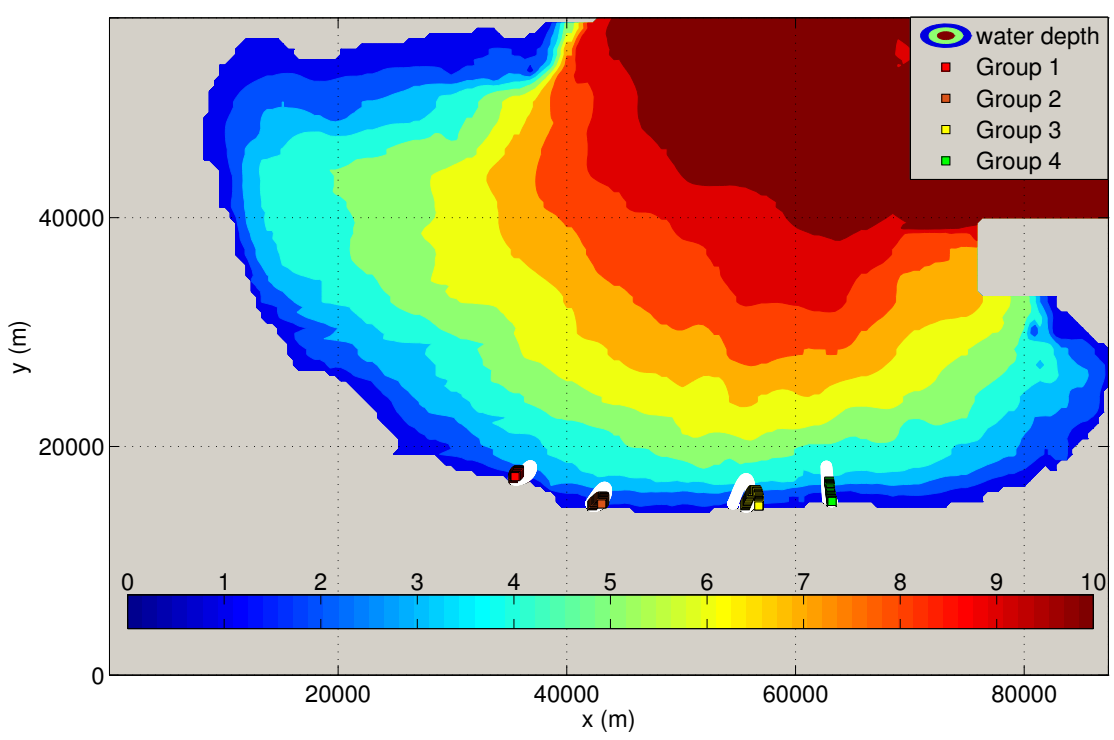

Figure 14. The trajectories of 4 particles during $12-18 \mathrm{~h}$.
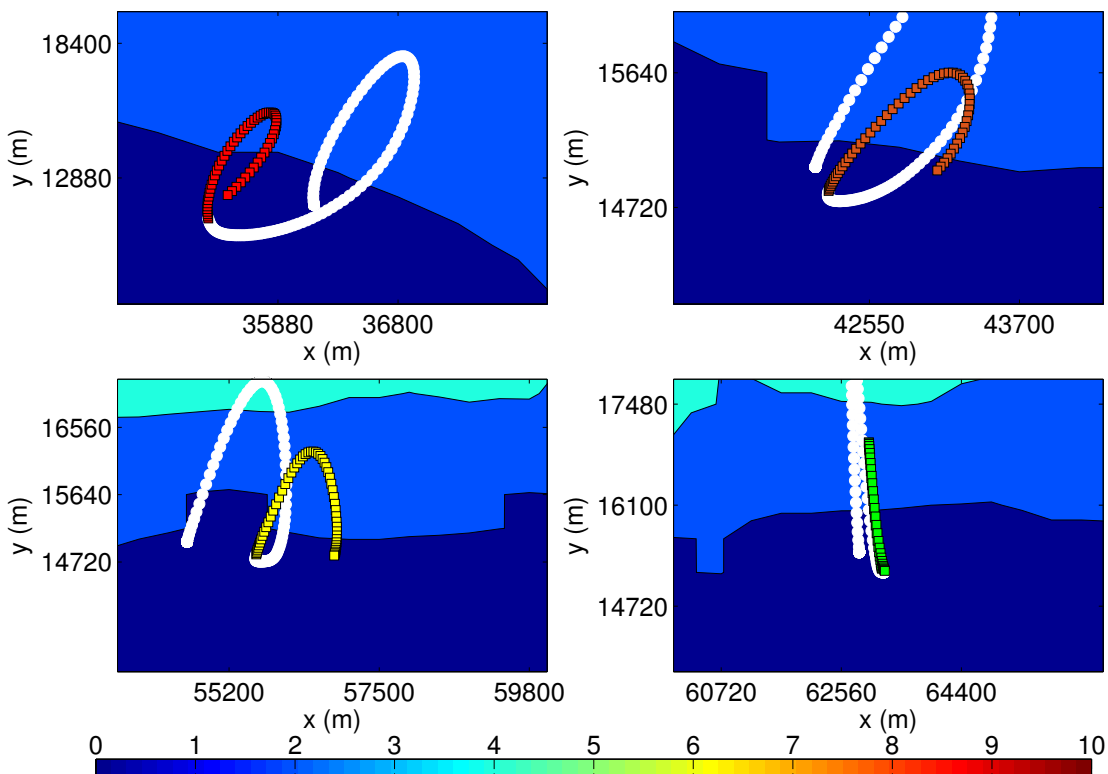

Figure 15. The amplified diagram of trajectories of 4 particles during 12-18 h.

In general, the transport distances of particles range from $5720 \mathrm{~m}$ to $9828 \mathrm{~m}$ and the absolute distances are within the range of 366-2031 $\mathrm{m}$ during $24 \mathrm{~h}$. The absolute distances of particles in Group 3 and 1 are 2031 and $1630 \mathrm{~m}$, followed by that in Group $4(514 \mathrm{~m})$ and in Group $2(366 \mathrm{~m})$. The transport distance of particles in Group 3 is the farthest $(9828 \mathrm{~m})$, being 1.7 times as long as that in Group $1(5720 \mathrm{~m})$. Although the absolute distances of particles in Group 4 and 2 are short, their transport distances reach $9693 \mathrm{~m}$ and $7335 \mathrm{~m}$. The transport distances of particles in Groups 1-4 near the releasing points are $2397 \mathrm{~m} \times 1224 \mathrm{~m}, 1354 \mathrm{~m} \times 1689 \mathrm{~m}, 2296 \mathrm{~m} \times 2461 \mathrm{~m}$ and $594 \mathrm{~m} \times 3104 \mathrm{~m}$, respectively. Among them, the transport distance of particles in Group 3 is the largest while in Group 4 is the smallest. If there were microplastic particles released from these four river mouths within $24 \mathrm{~h}$, it is reasonable to collect pollution particles within the scope of $2397 \mathrm{~m} \times 3104 \mathrm{~m}$ near the seashore. 


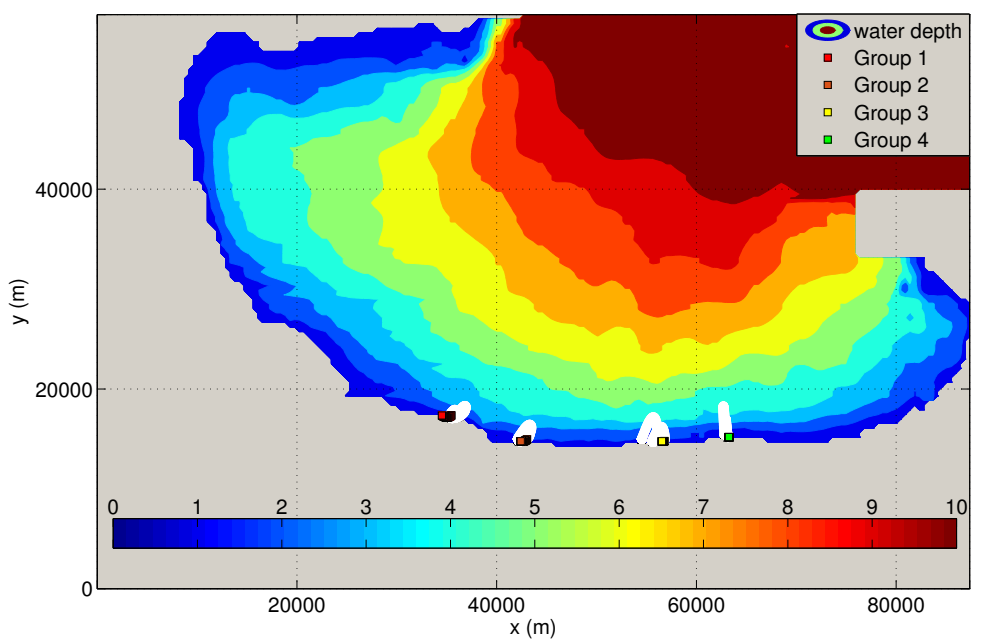

Figure 16. The trajectories of 4 particles during 18-24 h.
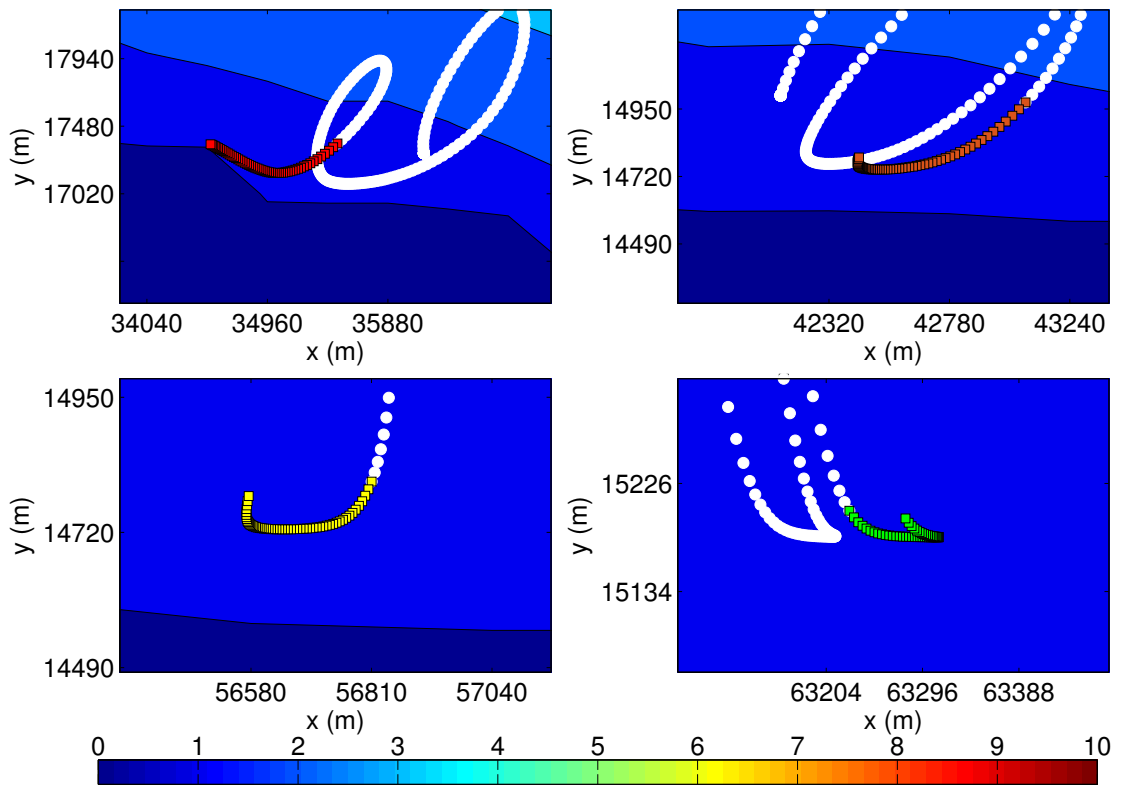

Figure 17. The amplified diagram of trajectories of 4 particles during 18-24 h.

4.2.2. Particles Input at $t=3,6,9 \mathrm{~h}$

The trajectories of particles in four groups released at $t=0,3,6$ and $9 \mathrm{~h}$ within $24 \mathrm{~h}$ are demonstrated in Figure 18. It can be seen that the moving ranges of the particles released at $t=9 \mathrm{~h}$ are the largest, being $4593 \mathrm{~m} \times 1952 \mathrm{~m}$ in Group 1, $2353 \mathrm{~m} \times 2618 \mathrm{~m}$ in Group 2, $2010 \mathrm{~m} \times 5670 \mathrm{~m}$ in Group 3 and $1270 \mathrm{~m} \times 8242 \mathrm{~m}$ in Group 4. These ranges are over twice than those particles released at $t=0,3$ and $6 \mathrm{~h}$, respectively, of which the moving ranges are similar, being $2398 \mathrm{~m} \times 1224 \mathrm{~m}$ in Group 1, $1355 \mathrm{~m} \times 1690 \mathrm{~m}$ in Group 2, $2297 \mathrm{~m} \times 2462 \mathrm{~m}$ in Group 3 and $595 \mathrm{~m} \times 3105 \mathrm{~m}$ in Group 4; $1591 \mathrm{~m} \times 1252 \mathrm{~m}$ in Group 1, $1555 \mathrm{~m} \times 1668 \mathrm{~m}$ in Group 2, $1345 \mathrm{~m} \times 2467 \mathrm{~m}$ in Group 3 and $325 \mathrm{~m} \times$ $3105 \mathrm{~m}$ in Group 4; $2307 \mathrm{~m} \times 1247 \mathrm{~m}$ in Group 1, $1957 \mathrm{~m} \times 1700 \mathrm{~m}$ in Group 2, $2236 \mathrm{~m} \times 2463 \mathrm{~m}$ in Group 3 and $421 \mathrm{~m} \times 3104 \mathrm{~m}$ in Group 4, respectively. Hence, it can be perceived that the microplastic particles released at $t=9 \mathrm{~h}$ can do little beneficial to the recycling process. 


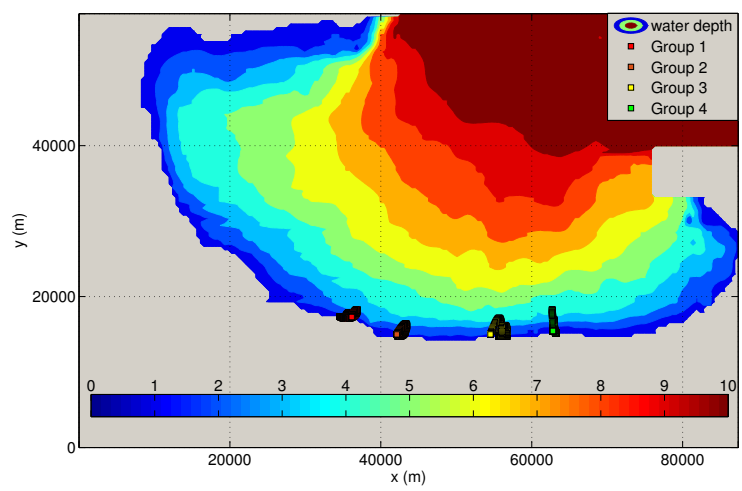

(a) Releasing at $t=0 \mathrm{~h}$

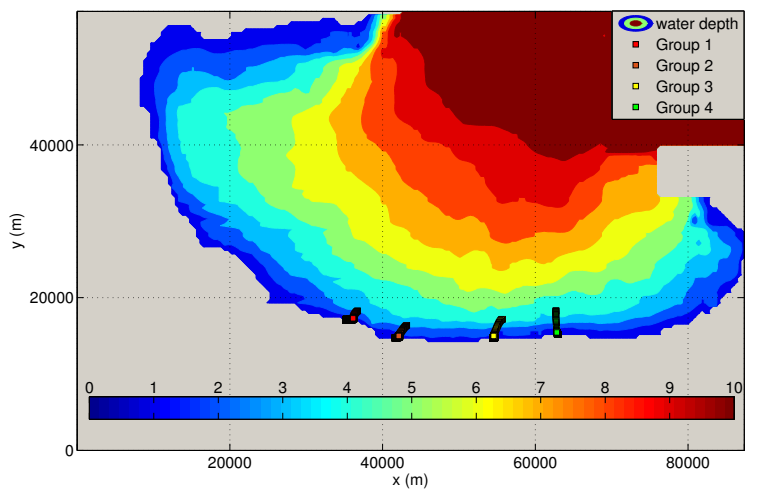

(b) Releasing at $t=3 \mathrm{~h}$

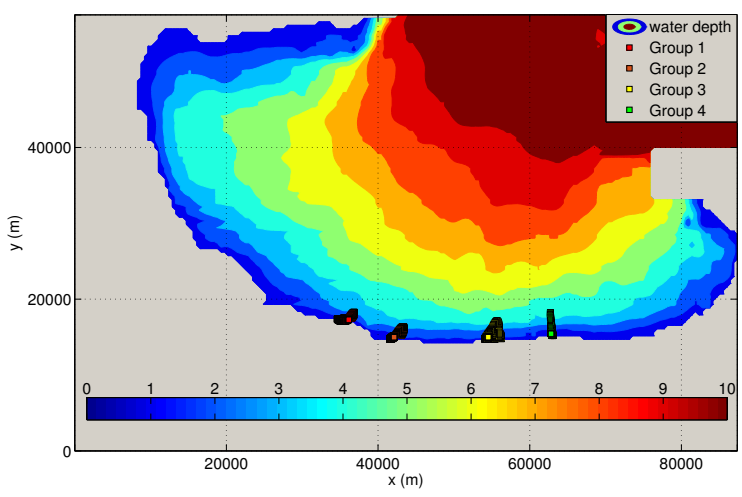

(c) Releasing at $t=6 \mathrm{~h}$

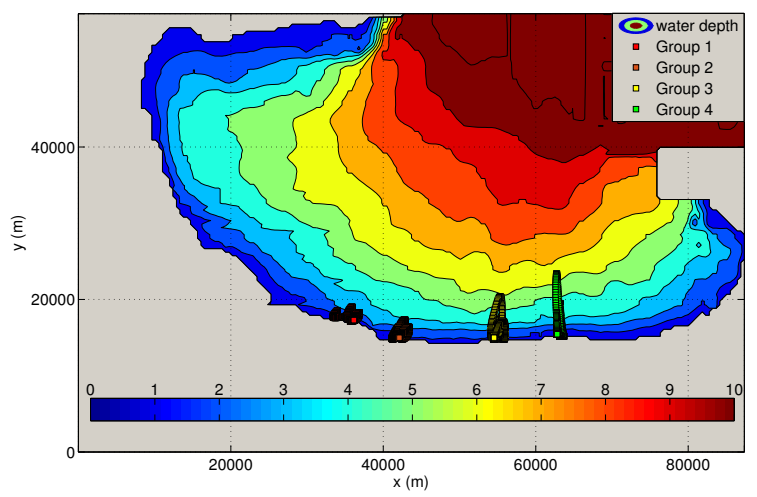

(d) Releasing at $t=9 \mathrm{~h}$

Figure 18. The trajectories of particles released at different time. 
The cumulative collision number of particles released at $t=3 \mathrm{~h}$ is the most, which is $1.01 \times 10^{5}$, followed by those released at $t=9 \mathrm{~h}\left(8.48 \times 10^{4}\right)$. The numbers of collision of particles released at $t=0$ and 6 h are only $4.05 \times 10^{4}$ and $3.32 \times 10^{4}$.

\subsubsection{Particles Input at $t=0 \mathrm{~h}$ within 30 Days}

Compared to the trajectories of particles within $24 \mathrm{~h}$, it can be seen in Figure 19 that the moving ranges of particles within 30 days expands obviously. The transport distances of particles in Groups 1-4 near the releasing points are $4732 \mathrm{~m} \times 1224 \mathrm{~m}, 2375 \mathrm{~m} \times 1709 \mathrm{~m}, 6393 \mathrm{~m} \times 2466 \mathrm{~m}$ and $3587 \mathrm{~m} \times$ $3105 \mathrm{~m}$, respectively. In $x$ direction, the transport distances of particles in Group 3 is the largest, while it is a relatively narrow range in Group 2 (2.7 times less than that in Group 3). Moreover, the particles in Group 4 have the widest transport distances in $y$ direction, 2.5 times larger than that in Group 1. Generally, the transport distance of particles in Group 3 is the largest. The scope of $6393 \mathrm{~m} \times 3105 \mathrm{~m}$ can be the minimal collect scope of microplastic particles releasing within 30 days.

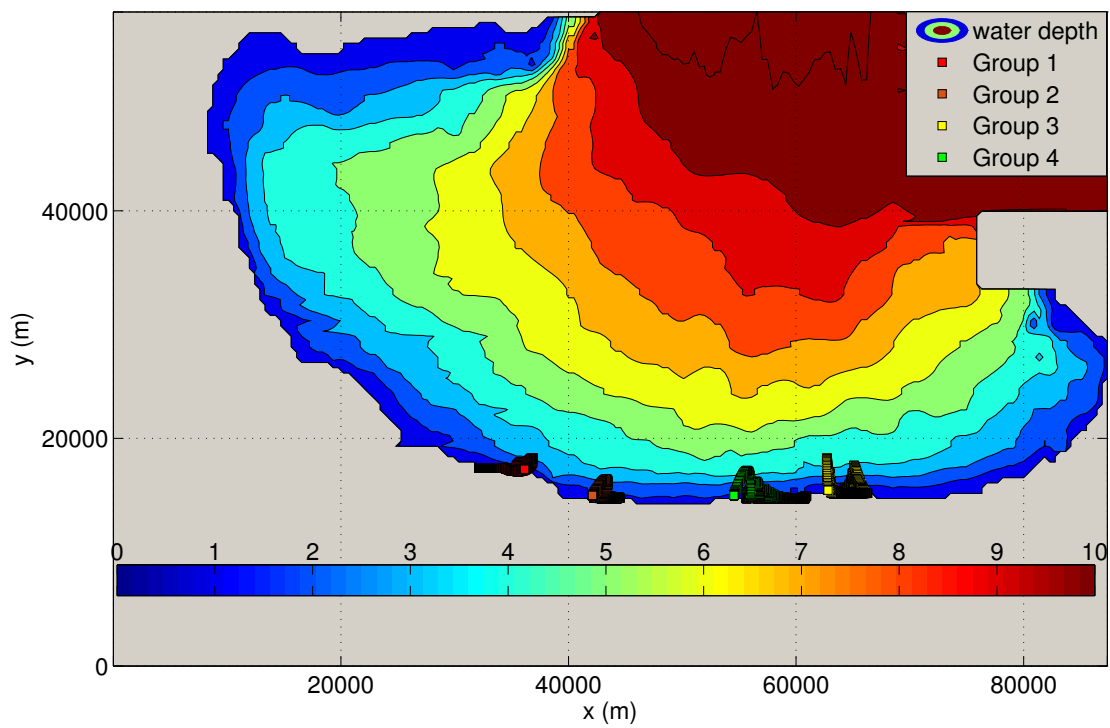

Figure 19. The trajectories of 4 particles in 30 days.

\section{Conclusions}

In this work, the movement trajectories of microplastic particles in Laizhou Bay are simulated based on the lattice Boltzmann framework coupled with the Lagrangian particle-tracking method. In addition to the current, inter-particle collisions and particle-wall collisions are also involved. After releasing, particles move forth and back with the changing tides. The trajectories of particles released at $t=0,3,6,9 \mathrm{~h}$ are recorded with tide boundary of $12 \mathrm{~h}$ period. The results show that the moving range of the particles releasing at $t=9 \mathrm{~h}$ is the largest, which is unfavorable for the recycle process of microplastics. The simulated results indicate that these particles normally drift within the scope of $4593 \mathrm{~m} \times 8242 \mathrm{~m}$ near the releasing point. Collisions indeed occur with as many as $3.32 \times 10^{4}$ within $24 \mathrm{~h}$, which has little effect on changing trajectories of particles. Even within 30 days, the transportation of these particles is still near the seashore and their moving ranges expand to $6393 \mathrm{~m} \times 3105 \mathrm{~m}$ from the releasing point.

Author Contributions: Conceptualization, H.L., W.Y. and Y.D.; methodology, H.L. and Y.D.; software, W.Y. and Y.D.; validation, Y.D.; resources, H.L.; data curation, H.L.; writing-original draft preparation, Y.D; writing-review and editing, H.L. and W.Y.; supervision, H.L.

Funding: This research was funded by the National Key R\&D Program (2018YFC1406401) and the National Natural Science Foundation of China (51779011).

Conflicts of Interest: The authors declare no conflict of interest. 


\section{References}

1. Arthur, C.; Baker, J.; Bamford, H. Proceedings of the International Research Workshop on the Occurance, Effects, and Fate of Mircroplastic Marine Debris; NOAA Technical Memorandum NOS-OR\&R-30; National Oceanic and Atmospheric Administration: Silver Spring, MD, USA, 2009.

2. Còzar, A.; Echevarría, F.; González-Gordillo, J.I.; Irigoien, X.; Úbeda, B.; Hernández-León, S.; Palma, A.T.; Navarro, S.; García-de Lomas, J.; Ruiz, A.; et al. Plastic debris in the open ocean. Proc. Natl. Acad. Sci. USA 2014, 11, 10239-10244. [CrossRef] [PubMed]

3. Ashton, K.; Holmes, L.; Turner, A. Association of metals with plastic production pellets in the marine environment. Mar. Pollut. Bull. 2010, 60, 2050-2055. [CrossRef] [PubMed]

4. Browne, M.A.; Galloway, T.S.; Thompson, R.C. Spatial patterns of plastic debris along Estuarine shorelines. Environ. Sci. Technol. 2010, 44, 3404-3409. [CrossRef] [PubMed]

5. Law, K.L.; Morét-Ferguson, S.; Maximenko, N.A.; Proskurowski, G.; Peacock, E.E.; Hafner, J.; Reddy, C.M. Plastic accumulation in the North Atlantic subtropical gyre. Science 2010, 329, 1185. [CrossRef]

6. Dubaish, F.; Liebezeit, G. Suspended Microplastics and Black Carbon Particles in the Jade System, Southern North Sea. Water Air Soil Pollut. 2013, 224, 1352-1360. [CrossRef]

7. Nor, N.H.M.; Obbard, J.P. Microplastics in Singapore's coastal mangrove ecosystems. Mar. Pollut. Bull. 2014, 79, 278-283.

8. Còzar, A.; Sanz-Martín, M.; Martí, E.; González-Gordillo, J.I.; Ubeda, B.; Gálvez, J.A.; Irigoien, X.; Duarte, C.M. Plastic accumulation in the Mediterranean sea. PLoS ONE 2015, 10, e0121762. [CrossRef]

9. Wiberg, P.L.; Smith, J.D. A theoretical model for saltating grains in water. J. Geophys. Res. 1985, 90, 7341. [CrossRef]

10. Niño, Y.; García, M.; Ayala, L. Gravel saltation: 1. Experiments. Water Resour. Res. 1994, 30, $1907-1914$. [CrossRef]

11. Lee, H.Y.; Lin, Y.T.; You, J.Y.; Wang, H.W. On three-dimensional continuous saltating process of sediment particles near the channel bed. J. Hydraul. Res. 2006, 44, 374-389. [CrossRef]

12. Tanaka, T.; Tsuji, M. Numerical simulation of gas-solid two-phase flow in a vertical pipe: On the effect of inter-particle collision. Gas-Solid Flows. ASME 1991, 121, 123-128.

13. Mei, R.; Hu, K.C. On the collision rate of small particles in turbulent flows. J. Fluid Mech. 1999, 391, 67-89. [CrossRef]

14. Yeganeh-Bakhtiary, A.; Shabani, B.; Gotoh, H.; Wang, S.S.Y. A three-dimensional distinct element model for bed-load transport. J. Hydraul. Res. 2009, 47, 203-212. [CrossRef]

15. Lin, J.H.; Chang, K.C. Particle Dispersion Simulation in Turbulent Flow Due to Particle-Particle and Particle-Wall Collisions. J. Mech. 2016, 32, 237-244. [CrossRef]

16. Fede, P.; Simonin, O. Direct Simulation Monte-Carlo predictions of coarse elastic particle statistics in fully developed turbulent channel flows: Comparison with deterministic discrete particle simulation results and moment closure assumptions. Int. J. Multiph. Flow 2018, 108, 25-41. [CrossRef]

17. Niño, Y.; García, M. Using Lagrangian particle saltation observations for bedload sediment transport modelling. Hydrol. Process. 1998, 12, 1197-1218. [CrossRef]

18. Chang, Y.; Scotti, A. Entrainment and suspension of sediments into a turbulent flow over ripples. J. Turbul. 2003, 4, 1-22. [CrossRef]

19. Bhatnagar, P.L.; Gross, E.P.; Krook, M. A Model for Collision Processes in Gases. I. Small Amplitude Processes in Charged and Neutral One-Component Systems. Phys. Rev. 1954, 94, 511-525. [CrossRef]

20. Liu, H.; Zhou, G.J.; Burrows, R. Lattice Boltzmann model for shallow water flows in curved and meandering channels. Int. J. Comput. Fluid Dyn. 2009, 23, 209-220. [CrossRef]

21. Zhou, J.G. Lattice Boltzmann Methods for Shallow Water Flows; Springer: Berlin, Germany, 2004 ; Volume 4.

22. Sun, T.; Li, W.; Dong, B. Numerical and experimental study on the motion characteristics of single bubble in a complex channel. Int. J. Comput. Fluid Dyn. 2015, 29, 346-356. [CrossRef]

23. Liu, H.; Zhou, J.G. Lattice Boltzmann approach to simulating a wetting-drying front in shallow flows. J. Fluid Mech. 2014, 743, 32-59. [CrossRef]

24. Chen, S.; Doolen, G. Lattice Boltzmann method for fluid flows. Annu. Rev. Fluid Mech. 1998, 30, 329-364. [CrossRef] 
25. Zhang, Y.; Li, H.; Wang, X.; Zheng, C.; Wang, C.; Xiao, K.; Wan, L.; Wang, X.; Jiang, X.; Guo, H. Estimation of submarine groundwater discharge and associated nutrient fluxes in eastern Laizhou Bay, China using 222 Rn. J. Hydrol. 2016, 533, 103-113. [CrossRef]

26. Chang, Y.; Hu, B.X.; Xu, Z.; Li, X.; Tong, J.; Chen, L.; Zhang, H.; Miao, J.; Liu, H.; Ma, Z. Numerical simulation of seawater intrusion to coastal aquifers and brine water/freshwater interaction in south coast of Laizhou Bay, China. J. Contam. Hydrol. 2018, 215, 1-10. [CrossRef]

27. Zhou, J.G. Enhancement of the LABSWE for shallow water flows. J. Comput. Phys. 2011, 230, $394-401$. [CrossRef]

28. Ding, Y.; Liu, H.; Peng, Y.; Xing, L. Lattice Boltzmann method for rain-induced overland flow. J. Hydrol. 2018, 562, 789-795. [CrossRef]

29. Yamamoto, Y.; Potthoff, M.; Tanaka, T.; Kajishima, T.; Tsuji, Y. Large-eddy simulation of turbulent gas-particle flow in a vertical channel: Effect of considering inter-particle collisions. J. Fluid Mech. 2001, 442, 303-334. [CrossRef]

30. Rong, Q.; Liu, J.; Cai, Y.Z.L.; Zhao, Z.; Yue, W.; Xia, J. Leaf carbon, nitrogen and phosphorus stoichiometry of Tamarix chinensis, Lour. in the Laizhou Bay coastal wetland, China. Ecol. Eng. 2015, 76, 57-65. [CrossRef]

31. Liu, H.; Zhang, J.; Wang, H.; Ding, Y.; Yi, Y. Numerical modeling of the tidal wave run-up and the eelgrass habitat at the Laizhou Bay. Ecol. Model. 2017, 360, 378-386. [CrossRef]

(C) 2019 by the authors. Licensee MDPI, Basel, Switzerland. This article is an open access article distributed under the terms and conditions of the Creative Commons Attribution (CC BY) license (http://creativecommons.org/licenses/by/4.0/). 